\title{
A Model Based Approach to School Shootings: Every Second Counts!
}

\author{
Hasan T. Arslan ${ }^{1, *}$ and Thomas Olsen ${ }^{2}$ \\ ${ }^{1}$ Criminal Justice and Security Department, Pace University, Pleasantville, NY 10570, USA \\ ${ }^{2}$ Police Officer Town of Mt Pleasant PD, 1 Town Hall Plaza, Valhalla, NY 10595, USA
}

\begin{abstract}
The cycle of violence invading our nation's schools has necessitated the training of law enforcement agencies. A breakdown in communications could mean an incident spirals out of control and results in catastrophic unnecessary loss of lives. Active communication can be accomplished between officers and their superiors, so that decisions are made in a manner that best pursues a rapid end to the threat posed by the perpetrator, and a rapid extraction of the injured. Authors have developed an effective nine-step response model for law enforcement agencies after examination of the real-time cases, infamous school-shooting incidents, in the United States.
\end{abstract}

Keywords: School shooting, communication, police response, model approach.

\section{INTRODUCTION}

"It is interesting to note that today's schools face many different problems from those of sixty years ago" (Duplechain and Morris, 2014, p.148). Since the Columbine High School shooting in 1999, every school shooting incident has been a reminder of the glaring epidemic of violence in our nation's schools. These incidents occurred all over the country, in forty of fifty states, in urban and rural areas. Victims come from all walks of life (Blair and Schweit, 2014). Indeed, President Obama noted in his remarks on October 1 , 2015 that, "Somehow this has become routine. The reporting is routine. My response here at this podium ends up being routine. The conversation in the aftermath of it. We've become numb to this" (2015, I 7).

Duplechain and Morris (2014) gathered a historic school shooting dataset from various newspaper reports in the U.S. that included 310 documented shootings on school property from 1760 until 2010. Specifically, there were 190 school shootings between 1990 and 2014 in this study. In 2014, the Federal Bureau of Investigation (FBI) released a dataset that included 160 active shooter incidents between 2000 and 2013; 39 of the incidents happened in educational environments that are divided into 27 schools and 12 institutions of higher education; 117 people were killed and 120 injured as a result of shootings in these places. During the first seven years of the FBI study, incidents occurred at an annual average rate of 6.4 in the final seven years of the study, incidents occurred at

*Address correspondence to this author at the Criminal Justice and Security Department, Pace University, Pleasantville, NY 10570, USA;

E-mail: harslan@pace.edu an annual average rate of 16.4 per year (Blair and Schweit, 2014).

Frankly, the coordination and decision-making process requirements for shooting incidents are immense and demand that effective strategies be devised. A breakdown in communications could mean an incident spirals out of control and results in catastrophic unnecessary loss of lives. The fact that many of these lives are likely to be innocent children should be further motivation for all law enforcement agencies to ensure they have trained their officers to be expert information gatherers and effective communicators in times of an unusual and sensational crisis. The law enforcement response to active shooters comes down to officers' training and proficiency with their weaponry, and their tactical skills to rapidly enter a building, move towards the threat, and eliminate it. Currently law enforcement officers are being taught variations of similar tactics in police academies across the nation. While the tactics vary from region to region and even department to department, officers are taught to immediately enter the scene and engage the suspect. Upon entering the premises, either by themselves or in small teams, officers are instructed to use their senses to locate and engage the suspect(s).

The cycle of violence invading our nation's schools has necessitated the training of law enforcement agencies and school employees to prepare for the protection of our children. Therefore, we aim to develop a master strategic plan based on the information revealed in the detailed examinations of police responses to the numerous recent and infamous school-shooting incidents. 


\section{ISSUES ON RESPONDING TO SCHOOL SHOOTINGS IN THE U.S.}

The Department of Justice (DoJ) through the FBI has adopted active shooter response guidelines for law enforcement in conjunction with a partnership with the Advanced Law Enforcement Rapid Response Training (ALERRT) initiative at Texas State University. In addition the Department of Homeland Security provides training opportunities and information regarding best practices for law enforcement responses to active shooting scenarios. Unfortunately it is not within budgetary possibilities for most departments to send all of their employees to federal, state, or even county level training programs. It is standard practice for internal department instructors to attend train-thetrainer sessions offered by various federal and state agencies and then return to their agencies and pass on the training. The New York State Division of Homeland Security and Emergency Services in conjunction with the National Center for Security and Preparedness is an example of a state level training opportunity for advanced active shooter response training.

Active communication between law enforcement officers as they arrive on the scene of a school shooting in progress requires extensive training. Law enforcement organizations around the nation should be conducting this training as often as time and budgets allow. Initial law enforcement training in active shooter response must begin in the basic recruit school. Police academies are run on the county and state level and the degree to which they exceed minimum standards varies from region to region.

Law enforcement response training for active shooters focuses on the importance of small team tactics and the necessity to enter the school building, or other shooting scenario area, and without delay move towards the sounds of gunfire to neutralize the threat. Officers are instructed that entering with less, possibly a single officer or two officers is more likely. Officers preparing to engage with those perpetrating an active massacre must be properly equipped, as perpetrators have proven to be heavily armed in many recent shootings. According to Adam Lankford, a criminal justice professor at the University of Alabama, "offenders in the U.S. were more likely to use multiple weapons and to carry out their rampages in schools or workplaces than were shooters in other countries" (Ziv, 2015). Budget considerations provide unfortunate limitations, but ideally officers should be equipped with high-powered rifles and sufficient spare ammunition.
Rifles provide highly accurate, long distance, and penetrating capabilities compared to the pistol. For example, a quick review of the infamous North Hollywood bank robbery in 1997 shows the true disadvantage officers face when not properly armed. Two bank robbers armed with semi-automatic rifles and thousands of rounds of ammunition were able to hold off a force of 350 LAPD officers armed only with pistols for 45 minutes (Justice, 2013).

Responding to a school-shooting event has several unknown variables: the location of the shooter, the number and location of the injured, and the location of remaining students and staff on campus (Paulison, 2014). For example, during Columbine High School shooting there were two perpetrators who attempted to set off homemade bombs and other incendiary devices. Initially, officers were faced with varying descriptions of the perpetrators and constantly changing locations, as well as no clear idea of how many suspects there really were. Upon the officers' later entry into the school, fire alarms were sounding, sprinklers were activated, and the building was an enormous maze. The mass exodus of students from the school building towards officers taking cover from the gunfire led to a vast array of witness accounts of what was occurring inside the building. In addition to not knowing how many suspects there were or where they were, there were reports of a possible perpetrator located on the roof (Stone and Dunaway, 2000). Thus, it is very important to understand which variables of the response by law enforcement are most important to a smooth and accurate flow of communication amongst officers on the scene. This requires an analysis of case studies of past incidents. Agnich (2015) points out that a systematic quantitative analysis is needed of shooting incidents to identify weaknesses that pose increasing security threats. While history may not repeat itself exactly, it is a mistake not to learn from past school shootings as well.

\section{METHODOLOGY}

This study employed cases from the following selected shooting incidents: Columbine High School (1999), Orange High School in North Carolina (2009), University of Alabama (2010), Sandy Hook Elementary (2012), Santa Monica College (2013), Washington Navy Yard (2013), and Umpqua Community College (2015). These cases were selected for two primary reasons: availability of information to the public and notoriety of incident. We believe that case studies are one of the best ways to develop an understanding to 
the real incidents. Thus, the selected cases were intensely analyzed to be established as an effective response model for law enforcement agencies. There are two research questions: How do officers communicate within and between agencies during school shootings? What factors influence their decision? To answer these questions, data is imperative in any evaluation or research to understand what is occurring and to build a foundation upon which to base any conclusions. A complete description of an actual school shooting event will allow for a thorough understanding of the active communication process among law enforcement officers. This will be analyzed as it has transpired in real events, and after comprehensive evaluation, a set of tactical considerations will be proposed as to how to more effectively respond during future incidents. No preparation is thorough without inclusion of the schools, as Bonanno and Levenson (2014) explain that school districts must form partnerships with law enforcement to achieve policy and program development for preventive measures.

In a case study, Martinson and O'Brien suggest that data when properly analyzed "...enable the researcher to synthesize, analyze, and highlight preliminary findings, themes, and lessons." (2010, p.177). The case study model "ensures that the issue is not explored through one lens, but rather a variety of lenses which allows for multiple facets of the phenomenon to be revealed and understood" (Baxter and Jack, 2008, p.544). More specifically, descriptive case studies allow one to see what has happened and why, allowing deeper examination and evaluation. An extensive description and analysis based on systematic and detailed data collection, preferably from firsthand accounts, will allow for a comprehensive understanding of the process (Martinson and O'Brien, 2010).

\section{TRAGEDY REPEATS ITSELF...AGAIN AND AGAIN!}

The response to the Columbine School shooting on April 20, 1999 in Littleton, Colorado proved to be a watershed moment in law enforcement response to school shootings. Leading up to and including the Columbine incident, law enforcement had been trained to respond to active mass murders and hostage incidents in a similar fashion. The response procedure consisted of containing the scene and establishing a perimeter while awaiting specially trained officers, known as SWAT. Based upon their training and experience, officers at Columbine immediately assisted the injured students they confronted outside the school and set up a perimeter to prevent the shooters from escaping. These first officers on scene also exchanged gunfire with the shooters who fired on the officers from their positions inside the school building (Stone and Dunaway, 2000). Setting up a perimeter and waiting nearly 40 minutes, as in the case at Columbine, is now viewed as unacceptable.

According to the official report by the Connecticut States' Attorney for the Judicial District of Danbury on the Shooting at Sandy Hook Elementary School, the perpetrator entered the building by shooting his way past the locked front doors of the school building. The Elementary School had practiced lockdown drills, but one was never officially initiated. Teachers began initiating their own classroom lockdowns after an intercom was activated, alerting others to the situation in the lobby where the perpetrator fired the first shots (Sedensky III, 2013). A discussion with Sgt. Matthew Brodacki of the Weston, PD (CT), who responded to the Sandy Hook School shooting, reveals even more challenges faced by first arriving officers. The large number of vehicles blocking the main driveway required many responders to run up a hill to reach the school building (Brodacki, personal communication, 2014, October 8).

The initial 911 call to law enforcement from school staff was received by the Newtown PD at 9:35 am and the first officer arrived within four minutes followed by two more Newtown officers thirteen seconds later. Gunshots were heard in the background as these officers arrived on scene. At 9:40 am a final gunshot was heard from inside the school and a minute later information was relayed regarding the possible location of that final gunshot as coming from near the front of the building. Newtown police officers entered the school building five minutes after the arrival of the first officer. Officers treated the remainder of the incident as if there were more than one perpetrator based upon the witness' statement (Sedensky III, 2013). The below model was developed after a strict examination of the real-time cases and the analysis has resulted in the development of nine vital steps to improve effective strategic police responses to mass shooting incidents.

\section{A NINE-STEP MODEL FOR AN EFFECTIVE RESPONSE STRATEGY}

\section{1) 911 Call for an Active Shooter in School}

The flow of information for both cases from a law enforcement perspective begins upon receipt of the first 911 calls. This is the first step, without which there 
is no response at all. The call taker receives the information and relays to responding officers, which is the first variable in the communication chain. Call takers elicit such vital information as the location and description of the suspects as well as how many suspects. A dispatcher may be able to gather additional information from different 911 callers and narrow down the location within a school building where the perpetrator(s) might be. This can save seconds when relayed to responding officers who must decide where to approach and enter a building. In a large school complex, this could potentially save many additional lives. The initial information gathered by call takers and then by arriving officers sets the stage for how the rest of the incident will unfold. For example, at Sandy Hook, and Columbine, there was never a clear idea of how many shooters were in the school buildings. Consequently, 911 call takers must be well trained so they do not become overwhelmed by a large volume of calls, and thus, lose out on valuable information collection. It should be impressed upon school staff that any staff member in a position to do so should call 911 and provide any information they have especially in regard to number of perpetrators, location, and description. This requires thoughtful observation while speculation and unspecific details only add to the confusion.

\section{2) Response Time}

The receipt of 911 calls results in the dispatch and response of police units. Even the most immediate, effective, and efficient dispatching of police in urban and suburban areas of the U.S. can take a couple of minutes for the dispatcher to gather sufficient information and deploy the nearest available units. There could be further delays in response due to location and traffic conditions. In rural areas where there is more distance to travel, it is probable the police response times are longer. Responding officers will immediately experience higher blood pressure and an adrenaline rush as they receive additional information that confirms an active shooter at a school. It is important that officers be prepared for this physiological response so that they can control their breathing and remain in control of their actions. Getting to the scene as fast as possible is imperative but a police vehicle accident does no one any good and takes an officer out of the fight before they even arrive, in addition to requiring a diversion of resources to assist an injured officer. Controlling the body's physiological and emotional responses will be even more important once the officer arrives on scene and transitions to the next step of immediate entry into the threat environment. In some cases there may even be more than one shooting scene, or an evolving chase. The Santa Monica College shooting began as a domestic shooting, then a carjacking and further shooting during the police chase and culminated in further shooting at Santa Monica College (Wilson et al., 2013). Any part of this incident alone would cause a high stress response, coupled together requires extraordinary professionalism.

\section{3) Immediate Entry}

Data shows that mass shooting incidents generally result in death and destruction that begins and ends within minutes. In 64 incidents where they were able to determine time frames, it was revealed that nearly $70 \%$ of the incidents ended in five minutes or less while 23 ended in two minutes or less (Blair and Schweit, 2014). This makes it clear that civilians who are already on scene are will be faced with life and death decisions on their own prior to police intervention. Therefore, it is imperative for the first officers to engage in an immediate response and not wait outside for more specialized units to arrive, which take precious time to assemble. A lone officer will be at a severe tactical disadvantage entering alone, but they must weigh this against the length of time that will pass before back up officers arrive. In many suburban areas, it can be expected that several law enforcement officers will arrive within minutes. It is important to highlight that these first responders might come from different jurisdictions like local, county, state and federal law enforcement agencies that are nearby. The likelihood for differences in training should dictate a brief "meeting of the minds" to ensure that whichever officers have decided to enter together are of the same tactical mindset of what their actions will include. In theory, it would be ideal for at least one officer to remain outside as the on-site incident commander until they can provide a situational report to the first supervisory officer to arrive on scene. This allows for a face-to-face direct report of how many officers are already on scene, which direction they entered, their intended direction within the building, as well as any other immediately pertinent information. In reality, it will be extremely difficult for any of the first officers to remain outside while their colleagues enter the building without them. Nonetheless it would aid in directly informing the first supervisory officer on scene, rather than the commanding officer having to rely solely on the continuous squawking of information and misinformation via radios. 
Responding officers at Columbine were distracted by their attempts to aid some of the grievously injured students who came their way. The fact that these officers were outgunned was the biggest factor preventing these officers from mounting any offensive from their positions, but the confusion in communications they encountered would not have made such an offensive push easy to accomplish given variances in the number of suspects, descriptions, and possible locations. It must also be considered that incendiary devices may be a part of the attack, as was the case at Columbine and Orange High School in Hillsborough (NC) where the shooter was armed with two pipe bombs and a smoke grenade (Karas, 2009). The introduction of incendiary devices and fire adds a whole different dimension. The activation of the fire alarm system due to fire, or to create fleeing panic, will also adversely affect officers as they make entry. The flashing strobe lights and extremely loud alert noises associated with fire alarms will result in a major disruption to clear and effective communications. Rapidly deactivating this system will solve more issues than its continued activation will solve.

A possible challenge on a school ground might emerge in the form of hard terrain and blockage on the access road in and out. Thus, keeping the roadway accessible is imperative to allow for the flow in and out of emergency medical services to transport the wounded. Triage and staging areas should be clearly established away from the scene for all to reference and to refer responding family members to. Comprehensive emergency incident planning should allow the incident commander to already have a predetermined number of potential locations in mind. First responders should also be staged after the initial response so that only the resources needed are on scene and accounted for.

\section{4) Confirmation of the Data from 911-Call Taker during Response}

According to former Illinois State Police officer Col. Michael Snyder, who was involved in an active shooter call at the Illinois State Capitol in the fall of 2005, "it was a mass confusion, the information constantly changes; communication tools, radio frequencies ... so many witnesses and so many people were involved, information conflicted and changed constantly" (Scullin, 2014). For example, the initial officers pinned down by gunfire at Columbine were faced with an overwhelming amount of conflicting and confusing information from frantic children as they fled the school building (Karas,
2009). Indeed, officers must work to overcome tunnel vision, auditory exclusion, as well as the inevitable communication difficulties encountered with portable radios in large, concrete buildings. While officers on scene are collecting a large amount of real time information about the incident as they seek out the perpetrator(s), they must decide which information has intelligence value and requires immediate transmission to superior officers. Supervisory officers who are on scene will be standing outside, or possibly even down the street out of view. An incident commander who receives misleading or no intelligence, from a policy making standpoint, will be forced to rely on his/her best guesses during the decision making process. A best guess is still just a guess and not an informed decision.

Following entry into the building, and during arrival and approach, officers must gather information from fleeing and secreted victims and witnesses. This involves normal witness interviewing but at a rapid, urgent, and far less formal pace. Any information that can be gained regarding the identity, number, location, weaponry of the shooter(s) along with their tactical capabilities are always very imperative in every stage of the counter-operation. This will require eliciting usable information from a frantic student or teacher who may be on the verge of total mental or emotional shutdown. It is also likely that some witnesses will be clinging on to life from severe injuries. Officers should provide first aid instructions to the victims and ablebodied victims who can assist the more seriously wounded, but it should not delay officers' advance towards the gunfire. This should be first aid instructions "on the run," while simultaneously gathering intelligence on the situation.

School buildings are commonly constructed using brick and mortar walls that may distort and preclude effective radio communications. Chief Lanier (2014) of the Washington Metro PD reported this type of construction as causing a problem with radio communications at the Washington Navy Yard shooting, a government building of similar construction to school buildings. Breakdowns in communications and the ability to share information can lead not only to friendly fire, but distorted or false suspect descriptions, and a breakdown of scene control. This may result in further loss of life, and even potentially an opportunity for suspects to escape the scene before apprehension.

\section{5) Search and Find the Perpetrator(s)}

Locating the perpetrator is the middle of the necessary process involving mass murder response, 
but it should be highlighted as the single most important mission of every officer who arrives on scene. In the same way that putting out a fire will save the rest of a building; locating and stopping the shooter will save the rest of the innocent lives at the scene. In practice, locating the shooter is a simple task. Anyone who has trained with, fired, or been near firearms knows the unmistakable sound of a firearm discharging and the smell of gunpowder in the air. Law enforcement officers have extensive training with firearms and need only to follow the sounds, smells, and even haze in the air that will lead them to the firearm at their source. The situation is clearly compounded if there is more than one shooter operating in a different area of the building. This may dictate that officers break down into smaller groups to split off into different directions while being cognizant of not turning the same corner on each other and engaging in friendly fire. While nearly all perpetrators have been males, a female was responsible for the shooting at the Huntsville campus of the University of Alabama (Powell, 2010). Officers must be mentally and physically prepared to engage in a firefight in close quarters with hordes of innocent victims hiding or fleeing down hallways.

\section{6) Engage and Neutralize the Threat}

The law allows for law enforcement officers to meet any perceived or actual deadly threat to themselves or others with deadly physical force. If a perpetrator has disarmed himself and surrendered then the suspect should be taken into custody and held to account in the criminal justice system. On the contrary, any perpetrator who continues to engage in deadly physical violence must be met with immediate deadly physical force from responding officers. Officers must be prepared with weapons that provide stopping power and precision accuracy. For example, at Columbine, there was a school resource officer on the campus who rapidly responded to the side of the school where a custodian had requested assistance. The officer immediately engaged one of the perpetrators from the parking lot; however this officer was quickly pinned down by incoming gunfire (Stone and Dunaway, 2000). Semiautomatic rifles are necessary in these scenarios. A tactical bag of additional loaded magazines must be readily available. Officers cannot arrive on scene or at the perpetrator's location and become pinned down by superior firepower from the perpetrator. This is not a war of attrition where officers can seek cover and hope to outlast the perpetrator. The first patrol officers on scene must immediately bring the fight to the enemy through violent and aggressive tactics. This intense police response will draw the perpetrator's attention away from the innocent lives in the school building and compel them to confront a superior law enforcement complement. Officers who arrived at Umpqua Community College in Oregon engaged in a firefight with the suspect at great peril to themselves, but this drew the shooter's attention to them rather than other students and ultimately led to the shooter's demise from a self-inflicted wound (Associated Press, 2015). Unless in close quarters, handguns are limited by their shorter range and diminished accuracy, particularly when officers are experiencing physiological stress. Shotguns have limited ammunition capacity and take longer to reload as well as a potential for collateral damage at longer ranges. Police officers must therefore quickly decide which weapon will be most effective given the scenario they face.

\section{7) Crime Scene Preservation and Security}

Securing the scene follows immediately after the securement of the perpetrator. Incident command should deploy law enforcement resources in small teams to search and clear the rest of the building. There should be an emphasis on locating any additional perpetrators as well as improvised explosive devices meant to decimate the emergency response. Additional perpetrators should be handled in the same manner as the first. Suspected improvised explosive devices should be urgently reported to the incident commanders and an immediate evacuation of the area near the device should be undertaken. A controlled perimeter must also be established outside the school complex to prevent any additional perpetrators from attempting to flee the building and escape the scene. Securing a large school complex is best accomplished by dividing the building into zones and/or divisions. As law enforcement personnel secure areas it will allow for emergency medical services to enter these warm zone and assist in evacuating injured victims and traumatized witnesses.

\section{8) Search for Survivors and Injured on the Scene}

The Committee for Tactical Emergency Casualty Care has translated lessons learned from the wars in Iraq and Afghanistan and applied them to what might be encountered in a school massacre environment. Analysis has shown from the battlefields of the Middle East that soldiers inflicted with traumatic injuries that rapidly lead to preventable deaths experienced $90 \%$ survival rates when rapid first aid was applied on scene 
before transport (Bobko and Kamin, 2015). Bullet wounds are penetrating traumatic wounds that can result in a catastrophic rapid loss of blood. We now know through the lessons learned by our extraordinary military that many deaths can be prevented through simple first aid interventions that will keep a victim alive long enough to reach advanced medical interventions at medical centers. Victims suffering from severe blood loss will require hemorrhage control to keep them alive to survive the transport to a hospital for emergency medical intervention. Other less severely wounded victims must be triaged and transported by EMS as resources are available to do so. It is important to consider that victims will not only suffer immediate physical injuries but also long term mental and emotional health issues. It is imperative that law enforcement officers be proficient in basic hemorrhage control. No victim who survives the attack should bleed to death waiting for EMS after the shooting has ceased.

Searching the crime scene for additional victims and hidden survivors will require a time consuming and tedious search of each and every space in the building where a person in fear for their life might consider hiding. No door should be left unchecked, and no storage space uninvestigated. This search will also serve as a final securement of the scene and will allow for the identification of pertinent evidence for the investigation. Following this canvass, the scene will be considered clear and secure and can be turned over to crime scene investigators for analysis and evidence collection.

\section{9) Threshold Assessment Report}

The final step is conducting an after action review and assessment of the incident from an operational standpoint. This constructive evaluation will highlight both the excellent work that was accomplished, as well as the areas that can be improved upon. This is important not only for the stakeholders involved, but would allow law enforcement agencies from across the country and the world to read a factual report of what occurred and how the response unfolded. These reports have served as learning opportunities both internally and externally for the law enforcement community. There should be no reason for police agencies to not learn from each other's good work and mistakes. An after action report should serve as a basis for future training, and tactical adjustments. The goal should be to accomplish these steps as quickly and effectively as possible so that the highest number of lives can be saved.

\section{POLICY RECOMMENDATIONS}

First and foremost, there must be existing "relationships between school officials and local lawenforcement and first-responder agencies long before disaster strikes. Response protocols should be clear and understood by all parties" (Duplechain and Morris, 2014, p.148). Police departments with schools within their jurisdiction should be assigning liaison or school resource officers to be the point of contact between those schools and their agency. The police department should have a blue print or marked layout of the school buildings with numbered classrooms. Classroom numbers should also be visible through the windows from the exterior of the building, allowing responding officers to respond directly to a specific classroom from the exterior if the situation requires. Officers should also be familiarizing themselves with their school campuses during their routine patrols. Patrol officers should conduct random checks of school campuses within their patrol post or sector during the course of their tours. Random checks serve the duel purpose of providing an unscheduled police presence that is difficult to anticipate and therefore dissuades potential criminals, while also forcing officers to become familiar with the campus layout.

Prevention is an area where education and law enforcement can both benefit from close collaboration as well. Law enforcement prevention capabilities are enumerated in the traditional sense of police investigating any reports received of erratic, questionable, or overtly homicidal or suicidal tendencies of students or anyone believed to pose a threat to a school's safety. Such police investigations and thereby preventive action is only possibly when it is reported. Many large urban police agencies have declared capabilities of monitoring social media, so there exists an opportunity for proactive law enforcement prevention in this arena, but monitoring the vast social media networks of adolescents, teenagers, and young adults is a task too big for the majority of suburban and rural law enforcement agencies. Therefore, prevention must be a team effort between law enforcement and educators. It is the educators who engage with the student population on a daily basis, and they can detect changing behaviors in their students. Educators know who the marginalized students are and who have violent tendencies or ideations. Kalish and Kimmel (2010) in their work on the sociological aspect of school killers note that male killers experience an aggrieved entitlement as a partial causation to their intent to kill all who have caused 
them to suffer. Having suffered at the hands of bullies, name callers, and being marginalized they strike back with explosive rage which is compounded by preexisting psychological issues, and access to firepower. The shooters resolve to establish their masculinity after long periods of hiding their emotions from the compounding effects of marginalization (Evans, 2016).

Following past shootings, similar lines can be found in new reports of the shootings from classmates, educators, and community members that the perpetrator was strange or marginalized or another characteristic that indicates perhaps someone should have seen this coming. This blame passing is meritless since no one will accept responsibility for not having "seen it coming". This is where an education and law enforcement investigative cooperation should serve to "see it coming" and prevent a homicidal blood bath of students before it happens. This is not to say that educators need report every bullied student to their law enforcement partners, rather that educators should examine the totality of the circumstances surrounding marginalized students who begin displaying troubling behavior warranting a report to law enforcement for investigation. Parents too bear responsibility in monitoring the mental, emotional, and sociological help too. Referencing a novel by Lionel Shriver, Evans (2016) explains that a grieving mother struggles to come to grips with what responsibility she bears for the horrific murders committed by her own son. This brings forth the point that parents or guardians play an integral role in monitoring the health of their children and any sudden violent tendencies.

Training for school staff is a responsibility of the school administration, but it is best accomplished in partnership with local law enforcement and emergency responders. These organizations with primary response responsibilities are best positioned to educate the school community on how to effectively respond to an active shooter. This may also provide local law enforcement personnel with the opportunity to train in the school and learn the layouts of the buildings. Training must begin at the basic level of tabletop discussions and involve understanding the dynamics of a chaotic, rapidly deteriorating and continuously evolving situation. Providing school staff with this baseline understanding will allow for additional hands on training to include participating in simulated response drills under the supervision of law enforcement experts.

No one can dispute that both the information and intelligence gathering process will be rapidly evolving, and that the analysis and decision-making by field commanders must also be expedient in order to have a positive outcome. If there is no active communication among the necessary stakeholders on scene and through the police dispatch, then further confusion may emerge from the chaos. Even initial confusion will serve only to further delay the actions of responding officers, and could hamper critical decisions by commanders such as the deployment of additional officers to the appropriate location. At any active shooter incident, every second counts, and effective active communication will decrease the potential for delayed tactics and instead potentially bring the event to a swift conclusion with a minimal loss of life.

Responding units to the scene will require a disciplined communication process even prior to their arrival. Police officers generally operate on only one radio communication frequency, which necessitates one person transmitting at a time for an audible transmission to be produced and received by others. Responding officers from neighboring jurisdictions may be on a different frequency or the same, but regardless will rely on the information disseminated by the original dispatchers. There is a great opportunity in these initial stages for there to be miscommunications that create further confusion and chaos rather than producing solutions. The likelihood that officers from various agencies will find themselves on scene together but with radios that operate on different frequencies is another immediate barrier to active communications. Command posts must be equipped with representatives from all involved agencies so that all radio communications are being monitored. Officers entering the school building who cannot maintain radio contact with each other must operate within visual or voice contact of one another. It would be prudent to ensure at least one member of each tactical team is capable of communicating with a member of separate teams in the building.

The entrance into the school building to neutralize the threat requires a degree of active communication among the initial group of officers, or lone officer and other officers who will soon join, that can only result from prior rehearsals. The officers must communicate the direction they are going in pursuit of the perpetrator, as well as the description and possible weapons of the perpetrator. A failure of communication here will have potentially devastating consequences even possibly resulting in friendly fire between responding officers. Patrol officers are generally easily identifiable by their uniform and equipment, but the 
presence of plainclothes officers can complicate this. These officers should have a jacket or vest available that can be worn to easily identify themselves as police officers and reduce the chance of a friendly fire incident.

Officers are trained to advance towards the sounds of gunfire, while attempting to gain any further information possible from any victims encountered. Injured victims must be passed over, in order to ensure a rapid advance on the shooting threat, victims are to be cared for after the threat has been secured. When tragedy strikes, it will be the teachers, administrators, and staff (e.g. custodians) who will face decisions that will not only impact their own lives but also those of the students. This is why the training of law enforcement officers and their responses to active shooter incidents are not the only concerns that must be addressed. The training of school personnel on their roles and responsibilities when dealing with an active shooter is just as important a consideration. High school age students are also capable of assisting in the response process, particularly when it comes to rendering first aid to the injured. Cardio Pulmonary Resuscitation (CPR) has been taught to civilians as a basic lifesaving skill and this same principle must be applied to teach basic medical interventions such as tourniquet application to stop traumatic arterial hemorrhaging. This could turn civilians at shooting scenes into lifesaving care givers, allowing law enforcement officers to prioritize their advance towards the perpetrator.

Citizens must be educated that they cannot expect initial law enforcement officers to tend to each and every medical emergency on scene. Crucial first aid for traumatic injuries must be treated by civilians helping each other until the threat is secured and police can commence evacuating the injured. This is an area where civilian first aid skills, including traumatic wound care and tourniquet application, must be promoted. Doctors of emergency medicine on hemorrhage control explain that, "delivering this lifesaving knowledge to public safety personnel, first responders, and ultimately to the lay public is of utmost importance....public education programs must be developed and promulgated, along with providing the necessary equipment to allow widespread civilian involvement" (White et al., 2016, \11).

\section{CONCLUSION}

It is hard to bring to our imagination any scene that could be more tragic and chaotic than the scene of mass murder at a school. The chaos of mass murder in a school building must be quelled by the law enforcement officers who arrive on scene. In addition, responding law enforcement officers must coordinate with other arriving first responders, especially emergency medical services. Even after the ensuing violence, school buildings are vast structures that will require numerous hours to be fully secured.

It must be the policy of law enforcement agencies to train and equip their front line patrol officers to respond instantly to mass murderers. Police agencies must implement an open dialogue with school administrators and staff to increase their awareness of safety and security threats and their ability to respond in the crucial minutes before emergency personnel arrive on the scene. The days of EMS standing by until a scene is entirely secure no longer applies to an active shooter or school massacre incident. Training and preparation for such a scenario is a necessity, while acknowledging that each incident will be inevitably different. This means that the first arriving officers must be proficient at gathering relevant information regarding what is occurring and where. Supervisory officers must be experts at receiving intelligence from the field and rapidly analyzing the unfolding incident. The active communication among law enforcement officers as they arrive on scene will determine how the incident unfolds and how coordinated the response will be among all first responders. In addition, the actions of leaders, individual teachers, and students within the school will have life altering consequences even before law enforcement officers arrive on scene. The school staff must be trained to think and act like civilian first responders rather than just being bystanders until a law enforcement presence takes hold. Schools that do not have a continuous police presence on their campus will be their own first responders until the arrival of law enforcement. Educating the school staff in civilian first response is the responsibility of local police and emergency medical personnel. This is part of ensuring that both the law enforcement agency and the school are properly prepared, and this will require the cooperation and support of the school district and local government leaders.

The purpose of active communications among law enforcement officers at a school shooting incident is to ensure the quickest, most effective end to the incident, while preserving each and every life possible. This will be accomplished by the communications between officers and their superiors, so that decisions are made in a manner that best pursues a rapid end to the threat 
posed by the perpetrator, and a rapid extraction of the injured to the appropriated medical facilities. Budgetary constraints may present an obvious obstruction to proper training and preparation for school shooting incidents, but that must not be allowed to serve as an excuse for failing to plan and prepare for a major jurisdictional tragedy.

\section{REFERENCES}

Agnich, L. (2015). A Comparative Analysis of Attempted and Completed School-Based Mass Murder Attacks. American Journal of Criminal Justice, 40(1), 1-22. http://dx.doi.org/10.1007/s12103-014-9239-5

Associated Press. (2015, October 7). Umpqua Community College gunman killed himself after police shot him: authorities. NBC News. Retrieve from http://www.nbcnews.com /storyline/oregon-college-shooting/umpqua-communitycollege-gunman-killed-himself-after-police-shot-him-n440256

Analysis of School Shootings. (2014, December 9). Every town for gun safety. Retrieved from http://everytownresearch.org/ reports/analysis-of-school-shootings/

Baxter, P., \& Jack, S. (2008). Qualitative case study methodology: study design and implementation for novice researchers. The Qualitative Report 13(4), 544-559.

Blair, J. P. (2014). Solo entry to an active shooting event is dangerous. Police Executive Research Forum, 3(7). Retrieved from http://www.policeforum.org/free-onlinedocuments

Blair, J. P., \& Schweit, K. W. (2014) A Study of active shooter incidents, $2000-2013$. Texas State University and Federal Bureau of Investigation, U.S. Department of Justice, Washington D.C.

Bobko, J. P., \& Kamin, R. (2015). Changing the paradigm of emergency response: The need for first-care providers. Journal of Business Continuity \& Emergency Planning, 9(1), 18-24

Bonanno, C. M., \& Levenson Jr., R. L. (2014). School shooters: History, current theoretical and empirical findings, and strategies for prevention. SAGE Open, http://dx.doi.org/10.1177/2158244014525425

Duplechain, R., \& Morris, R. (2014). School violence: reported school shootings and making schools safer. Education, 135(2), 145150.

Evans, R. T. (2016). "Faggots, Fame and Firepower": Teenage Masculinity, School Shootings, and the Pursuit of Fame. Canadian Review of American Studies, 46(1), 1-21. http://dx.doi.org/10.3138/cras.2014.018

Justice, J. M. (2013). Active Shooters: Is Law Enforcement ready for a Mumbai style attack? Naval Postgraduate School. Monterey, CA. Retrieved from www.hsdl.org

Kalish, R., \& Kimmel, M. (2010). Suicide by mass murder: masculinity, aggrieved entitlement, and rampage school shootings. Health Sociology Review, 19(4), 451-464. http://dx.doi.org/10.5172/hesr.2010.19.4.451

Karas, B. (2009, August 21). Man obsessed with Columbine convicted of murder. CNN. Retrieved from http://www.cnn.
com/2009/CRIME/08/21/north.carolina.castillo.trial/index.html ?eref=rss_us

Lanier, C. (2014). Critical issues in policing series: the police response to active shooter Incidents. Police Executive Research Forum. Retrieved from http://www.policeforum.org /critical-issues-series

Martinson, K., \& O'Brien, C. (2010). Conducting case studies. In J. S Wholey, H. P. Hatry, \& K. E. Newcomer (Eds.), Handbook of Practical Program Evaluation (pp. 163-181). San Francisco, CA: Jossey-Boss.

Obama, B. (2015, October 1). Statement by the President on the shootings at Umpqua Community College, Roseburg, OR. The White House: Office of the Press Secretary. Retrieved from https://www.whitehouse.gov/briefing-room/speechesand-remarks

Paulison, D. (May 2014). "Mind the (supply) details: do you have the right power supply, communication equipment to get through natural and man-made disasters?" Law Enforcement Technology, 34+. Criminal Justice Collection. Web. 24 May 2016.

Powell, J. (2010). Saturday press conference on campus shooting First Alert 48 WAFF. Retrieved from http://www.waff.com/ Global/story.asp?S=11983009

Scullin, S. (May 2014). "The business of active shooter prep: how many ways do you train?" Law Enforcement Technology: 24+. Criminal Justice Collection. Web. 24 May 2016.

Sedensky III, S. J. (2013, November 25). Report of the State's Attorney for the Judicial District of Danbury on the shootings at Sandy Hook Elementary School and 36 Yogananda Street, Newtown, Connecticut on December 14, 2012. Retrieved from http://www.ct.gov/csao/lib/csao/Sandy_Hook_ Final_Report.pdf

Stone, J. P., \& Dunaway, J. A. (2000, May 15). Columbine Report Jefferson County Sheriff's Office. Retrieved from http://staff.jeffcolibrary.org/columbinecd/Columbine\%20REP ORT/Pages/TOC.htm

U.S. Department of Homeland Security. (2008). Active shooter - how to respond. Retrieved from https://www.dhs.gov/xlibrary/ assets/active_shooter_booklet.pdf

Vanderhart, D., Johnson, K., \& Turkewitz, J. (2015, October 1). Oregon shooting at Umpqua College kills 10, Sheriff says. The New York Times. Retrieved from http://www.nytimes. com/2015/10/02/us/oregon-shooting-umpqua-communitycollege.html? $r=1$

White, E., Cash, C., Augustine, J. J., \& Fowler, R. L. (2016, April 6). Tourniquets in field management of active bleeding. Journal of Emergency Medical Services. Retrieved from http://www.jems.com/articles/print/volume-41/issue40/special-focus-gearing-up-for-active-shooter-tactical-highthreat-incidents/tourniquets-in-field-management-of-activebleeding.html

Wilson, S., Levs, J., \& Martinez, M. (2013, June 9). Santa Monica shooting victim dies, bringing toll to 5 . CNN. Retrieved from http://www.cnn.com/2013/06/09/justice/california-collegegunman/

Ziv, S. (2015, September 11). "Study: Mass Shootings 'Exceptionally American Problem'; U.S. has less than five percent of world's population, but had 31 percent of mass shootings in 19662012." Newsweek Criminal Justice Collection. Web. 24 May 2016.

Received on 06-08-2016

Accepted on 01-09-2016

Published on 20-09-2016

\section{DOI: http://dx.doi.org/10.6000/1929-4409.2016.05.15}

(C) 2016 Arslan and Olsen; Licensee Lifescience Global.

This is an open access article licensed under the terms of the Creative Commons Attribution Non-Commercial License (http://creativecommons.org/licenses/by-nc/3.0/) which permits unrestricted, non-commercial use, distribution and reproduction in any medium, provided the work is properly cited. 